Данг С.Ж.

Повышение роли профсоюзов вьетнама

по осуществлению социальной зациты трудящихся

\title{
Аннотация
}

В статье рассмотрена проблема повышения роли профсоюзов во Вьетнаме по осуществлению социальной защиты трудящихся.

Ключевые слова: профсоюз, социальная защита, роль, трудящиеся.

\section{Dang X.G. \\ Increasing the Role of Vietnam's Trade Unions in Implementing the Social Protection of Employees}

\section{Abstract}

The article examines the increasing role of trade unions in Vietnam in the implementation of social protection of employees.

Keywords: personality, mental development, psychological health, mental health.

$\Pi$ ереход к рыночным отношениям с сохранением социалистической ориентации и устремлениями интеграции в мировую экономику потребовал переосмысления роли профсоюзов в новых условиях хозяйствования. Если при существовании плановой экономики с ее государственным и коллективным секторами усилия профсоюзов были нацелены на комплексное улучшение жизни трудящихся - материальной и духовной, то избранный путь построения многоукладной экономики выдвигает уже иные задачи, при решении которых должно быть учтено и эффективное развитие самой экономики, ее индустриализации и модернизации, и повышение уровня и качества жизни работников, а также соблюдение принципов демократии и социальной справедливости, которые будут способствовать формированию сильной страны.

Профсоюз продолжает оставаться важной общественно-политической силой, представляющей и защищающей интересы трудящихся, он соединяет народ с Партией, которой принадлежит руководящая роль в управлении государством, действует под ее руководством и при этом сохраняет определенную самостоятельность, что позволяет профсоюзу глубже осмысливать изменение своей роли в построении стабильных, прогрессивных и гармоничных трудовых отношений, активно участвовать в социально-экономическом развитии страны.
Отношения профсоюза и государства продолжают выстраиваться на конструктивной основе с тем, чтобы совместными усилиями обеспечить благоприятные условия для дальнейшего развития экономики и общества, всего трудового народа. Но при этом именно на профсоюз ложится вся полнота ответственности за то, чтобы отыскать такие формы своей деятельности, которые смогли бы, с одной стороны, защитить работников в условиях возможной их эксплуатации, что таится в самих рыночных отношениях, а с другой - обеспечить экономический рост.

Защитить работников в условиях рыночной экономики даже при условии сохранения социалистической ориентации способен только профсоюз, других субъектов просто нет и быть не может. Государство, безусловно, по своей природе заинтересовано в осуществления заботы о своем народе, но у государства все же иные функции. А защита интересов трудящихся может обеспечиваться только коллективными усилиями их самих, благодаря чему и исторически появился на свет этот социальный институт - профсоюз. Отстаивая интересы наименее защищенной части населения в сфере труда, он делает саму систему трудовых отношений более равновесной.

В результате такого, столь довольно неблагополучного положения работников на предприятиях негосударственного сектора стал наблюдаться стреми- 
тельный рост забастовок, которые преимущественно носили стихийный характер.

Профсоюзы по разным причинам не всегда могли включиться в это забастовочное движение с тем, чтобы осуществлять это в цивилизованном виде - с помощью переговоров и возможностью избежать их последствий.

Объяснение этому следует искать в далеко не всегда эффективной деятельности профсоюзов: в том, что не везде заключаются коллективные договоры, которые к тому же не отражают полноты обеспечения социальной защищенности; не заключаются договоры о социальном и медицинском страховании; не осуществляется полноценного контроля за соблюдением режима оплаты труда и техники безопасности; а также в слабой подготовленности самих профсоюзных деятелей, которые должны повышать общественно-политическую грамотность работников и знакомить их с действующим законодательством в сфере труда.

В дополнение следует заметить, что пока имеет место несовершенство самой законодательной системы, недостаточно полно разработаны нормативные документы по технике безопасности труда, далек от совершенства и механизм трехсторонних отношений между государством, работодателями и работниками. Но вера в силы профсоюзов остается высокой даже у работодателей, тем более что государственное вмешательство в вопросы, находящиеся в ведении профсоюзов все же ограничено, и это касается, прежде всего, контролирующих функций по обеспечению правил по технике безопасности труда.

Поэтому, как представляется, профсоюзу необходимо сосредоточить свое внимание на нескольких важных вопросах, от решения которых может зависеть не только выполнение ими своих основных функций, но и процветание всей страны. Эти вопросы должны касаться взаимодействия профсоюзов с работодателями, с государством, с работниками, а также внутри самой профсоюзной деятельности, и все эти вопросы с необходимостью должны быть согласованы между собой.

1. Взаимодействия с работодателями. Профсоюзу необходимо отыскать пути наиболее эффективного взаимодействия с новыми предпринимателями, которые реально испытывают трудности и не всегда могут осознавать, какими путями можно добиться экономических успехов, не используя методы жесткой эксплуатации трудящихся. Очевидно, что предпринимателям вряд ли нужны забастовки, которые являются следствием непомерной эксплуатации и приводят к еще большей дезорганизации производственной деятельности, поэтому они объективно могут быть заинтересованы в установлении конструктивных социальных отношениях с профсоюзами.

Профсоюз может взять на себя функции обеспечения профориентации и профподготовки работников с тем, чтобы работники могли работать эффективно и сумели оценить свою объективную значимость для предприятия. Предприятию при этом может быть выгодно, не затрачивая дополнительных средств, получить специалиста более высокого профиля с тем, чтобы он мог не только качественно выполнять свою работу, но и при необходимости оказывать помощь и давать советы по усовершенствованию деятельности предприятии.
При этом профсоюз может не только обеспечивать работников профессиональными знаниями, но и знаниями по действующему законодательству, актуальность чего была выявлена в ходе проведенного исследования. Это может быть полезным и для самого предпринимателя, которому нередко не хватает этих знаний, а также в дальнейшем поможет ему избежать возможных негативных последствий от собственных неправомерных действий.

Работодатели должны и сами принимать активное участие в распространении среди работников знаний по действующим законам, связанным с трудовой деятельностью, а также знакомить их с правилами внутреннего распорядка предприятия с первых же дней поступления на работу, чтобы работники при отстаивании своих интересов могли опираться на эти правила и действующее законодательство.

При заключении трудовых соглашений для профсоюза также важно не просто отстаивать законные права трудящихся, включая в них наиболее актуальные на современном этапе социально-экономического развития пункты, но и обеспечивать реализацию интересов предпринимателя - в соответствии с передовой практикой экономически развитых стран.

Необходимо, чтобы руководители предприятий поняли, что без защиты интересов работников им не удастся привлечь на предприятия высококвалифицированных работников, поскольку неизменно будут возникать трудовые споры, забастовки и это, в конечном счете, негативно скажется на интересах инвесторов и экономическом развитии страны. Но при этом работодатели должны реально прочувствовать выгоду и помощь от профсоюзов, тогда они будут охотнее создавать их на предприятиях и совместно с ними выстраивать социально-трудовые отношения. Таким образом, знание законов и оказание профсоюзом помощи в формировании более эффективной производственной деятельности уже может служить залогом того, что забастовочное движение пойдет на спад и удовлетворенность работников увеличится.

2. Взаимодействия с работниками. Профсоюзы должны не только выполнять свои основные функции: 1) защитную (защиту прав трудящихся), 2) управленческую (привлечения работников к управлению деятельностью предприятия), 3) образовательную (обеспечивать их профессиональными знаниями, знаниями законодательных и нормативных документов), но и отыскивать новые формы их реализации.

Выстраивая конструктивные отношения с работодателями, профсоюз, по сути, обретает возможность защищать права работников наиболее эффективным способом. Профсоюз помогает работникам в подписании коллективных договоров в соответствии с законом о правах и интересах двух сторон и одновременно контролирует осуществление трудовых переговоров. Любые спорные моменты при этом могут быть успешно обсуждены и с работодателем, и со всем трудовым коллективом и найдены взаимовыгодные решения.

Но, прежде всего, профсоюз должен сосредоточить свое внимание на объяснении трудящимся преиму- 
ществ рыночной экономики при сохранении социалистической ориентации, содействовать пониманию ими того, что в условиях переходного периода могут сохраняться нерешенные проблемы. Имеет также место несовершенство социально-экономических и трудовых отношений, а переход к цивилизованным рыночным отношениям потребует усилий от всех субъектов рыночной экономики: государства, работодателей, профсоюза и самих работников.

В рамках деятельности консультативных центров профсоюз может оказывать помощь трудящимся в том, чтобы они воспринимали трудовую деятельность как почетную вне зависимости от того, на государственном или частном предприятии они работают. Он также должен способствовать тому, чтобы работники могли по-новому взглянуть на выбор профессии и формирование своей профессиональной карьеры. И здесь будет крайне важна помощь в подготовке и повышении квалификации с тем, чтобы работник почувствовал себя уверенней в завтрашнем дне и смог самостоятельно формировать стратегию своей профессиональной деятельности. Помимо этого, профсоюзу также важно осуществлять информирование работников по действующему законодательству, по тем документам, которые регламентируют его трудовую деятельность.

Профсоюз должен стимулировать трудящихся к повышению своей квалификации с тем, чтобы они смогли не только заботиться о своем профессиональном росте, но и использовать ресурсы самого предприятия, современные технологии для развития производства, повышения его экономической производительности. А это, в свою очередь, будет побуждать работников осознавать гордость за свою причастность к деятельности данного предприятия, к выпуску качественной продукции.

В политике построения развитой и эффективной экономики Вьетнама и ее постепенной интеграции в мировую экономику, как показывает опыт экономически развитых стран, профессиональное обучение и повышение квалификации начинает играть исключительно важную роль. Поэтому именно образовательная функция сегодня наполняется новым содержанием, что позволит профсоюзу не только обеспечивать социальную защиту трудящихся, но и привлекать их к управлению предприятием, обеспечивать совмещение интересов работодателей с работниками и в соответствии с государственной политикой.

Для того чтобы профсоюзы могли действовать более успешно в деле защиты прав трудящихся, не менее важным оказывается проведение пропагандистской работы о роли профсоюзов на предприятиях. К сожалению, не только работодатели и работники, но даже некоторые члены профсоюза на предприятиях негосударственного сектора не в полной мере понимают важности роли профсоюзов.

Поэтому требуется повысить уровень знаний работников о профсоюзе, особенно о его роли как представителя интересов работников с тем, чтобы работники более сознательно вступали в профсоюзы и принимали участие в профсоюзном движении. Необходимо распространять среди профработников и трудящихся резолюции КПВ, государственные законы, особенно
Кодекс о труде 2012 года, Закон о профсоюзной организации и постановления, циркуляры, связанные с двумя вышеупомянутыми законами, резолюции профсоюза об укреплении рабочего класса, о роли, функциях и задачах профсоюзов всех уровней.

Пропаганда роли профсоюзов по защите интересов работников, что особенно актуально на предприятиях негосударственного сектора, может осуществляться в самых разнообразных формах. Здесь могут использоваться: система внутреннего радиовещания, информационная доска предприятия, средства массовой информации и многие другие, в том числе включающие в себя развлекательный компонент, например викторины, художественно-культурные мероприятия и др. Также могут создаваться специальные информационно-консультативные центры, которые будут оказывать консультации по «горячей линии», что не займет у работника много времени и не потребуют больших материальных затрат. Однако, как показывает практика, самым популярным и эффективным способом выступает устная пропаганда, поскольку пропагандист может объяснить работникам что-то напрямую, отвечать на вопросы и способствовать обмену мнениями между работниками.

В дополнение к этому, а также к осуществлению более полноценной деятельности по формированию трудового коллектива на предприятиях, профсоюзы могут проводить разнообразные мероприятия, посвящённые знаменательным национальным датам (концерты, спортивные состязания, лектории и др.). Это будет способствовать не только воспитанию чувства патриотизма у трудящихся, но и их сплоченности в деле построения процветающего Отечества, формированию их гражданской позиции.

3. Взаимодействия с государством. Профсоюзу необходимо активнее включаться в усовершенствование управления государством, экономикой и обществом. Учитывая несовершенство действующего законодательства и установленную законодательную инициативу профсоюзов, а также, их тесный контакт с работодателями и работниками, они могут разрабатывать и предлагать государству законопроекты, которые могли бы способствовать усовершенствованию социально-трудовых отношений с учетом интересов всех субъектов взаимодействия и с целью дальнейшего социально-экономического развития общества.

Так, например, профсоюз уже участвовал в разработке дополнений в Трудовой кодекс, Закон о Профсоюзе, Закон о социальном страховании; в правовые нормы по развитию демократии в негосударственных предприятиях; в законодательство по охране и обеспечению безопасности труда, охране окружающей среды.

В настоящий момент для укрепления профсоюзной деятельности, прежде всего, представляется необходимым в законодательном порядке установить обязательность создания профсоюзных организаций в тех из них, где численность работников превышает 10 чел, особенно это актуально для предприятий негосударственного сектора. И, согласно пожеланиям работников этих предприятий, включая предприятия с иностранными инвестициями, сделать обязательным 
заключение коллективных договоров, а, кроме того, договоров о социальном и медицинском страховании.

В законодательном порядке также потребуется установление обязательств работодателей не только вовремя выплачивать заработную плату, но и осуществлять выплаты за переработку, а также корректировать заработную плату с учетом инфляции. Эти положения могут быть включены в действующий Трудовой кодекс.

Одним из важных моментов для современного этапа общественного развития является рост безработицы, который негативно сказывается на успехах общественных преобразований. Поэтому необходимо уделять серьезное внимание обеспечению занятости рабочих и уменьшению количества безработных, а для этого требуется установление конструктивных отношений и с работодателем, и с работниками и, прежде всего, на предприятиях негосударственного сектора.

Защита интересов трудящихся на предприятиях негосударственного сектора, как субъекта новых экономических отношений, где наиболее ярко проявляются все противоречия рыночных отношений - это ведь задача не только работников, работодателей и профсоюзных организаций, но и партийных, государственных органов. Поэтому для ее успешного выполнения оказывается важной тесная и эффективная координация всех управляющих органов и властей на всех уровнях. Необходимо также регулярно проводить диалоги между государством, союзами предприятий, инвесторами и владельцами предприятий - с целью укрепления сотрудничества всех сторон, для своевременной ликвидации возникающих трудностей, для создания гармоничных, стабильных, прогрессивных трудовых отношений и развития производства. По сути дела, сами рыночные отношения более четко структурируют трехсторонние отношения между работодателями, работниками (и профсоюзами, как их представителями) и государством.

Профсоюзы, с одной стороны, несут в массы политику Партии и государства, разъясняют ее членам профсоюза и всем работникам. А с другой стороны, именно они аккумулируют и доносят пожелания работников в партийный комитет, чтобы властные органы смогли дополнить и запланировать руководящие принципы и политику в соответствии с этими пожеланиями и с конкретными условиями в каждый период.

Профсоюзы также активно участвуют в построении разных видов политики, в той или иной мере затрагивающих интересы трудящихся, в контроле над их реализацией. Это касается жилищной политики, что особенно важно для работников промышленных зон, работников с низким доходом, политики обеспечения занятости, формирования шкалы заработной платы, социального и медицинского страхования, строительства детских садов и культурных учреждений для работников, политики в отношении женщин-работниц, политики по обучению и профессиональной переподготовке работников, политики поощрения работников учиться и совершенствоваться, повышать свое образование, квалификацию, уровень знания иностранных языков, а также в построении специальной политики для высококвалифицированных и инициативных работников.
Для повышения эффективности взаимодействия профсоюзов с государством необходимо регулярно устраивать встречи между руководителями государственных органов, профсоюзом, работодателями и работниками для усовершенствования деятельности профсоюза по защите интересов работников на предприятиях негосударственного сектора.

4. Взаимодействия внутри профсоюзов. Профсоюзы сегодня действуют на основе установленной правовой системы, в том числе: Конституции, Закона о профсоюзе, Трудового кодекса, Закона о предпринимательстве, административно-правовых решений и других положений местного законодательства, и в соответствии с этими нормативными документами реализуют демократические принципы в своих организациях. Тем не менее, в деятельности профсоюза могут наблюдаться некоторые недостатки, обусловленные переходом к рыночной экономике.

Сами общественные преобразований в сторону демократизации и построения рыночной экономики социалистической ориентации требуют повышения активности деятельности низовых профсоюзов. Именно низовой профсоюз может считаться базой для развития профсоюзной деятельности, поскольку непосредственно там реализуются функции профсоюзов, претворяется в жизнь политика партии и законы государства, а также постановления вышестоящей профсоюзной организации, и там же формируется сильный рабочий класс. При этом, как стало очевидным в результате исследования, наибольшее внимание следует уделять деятельности профсоюзов на предприятиях негосударственного сектора, который развивается стремительно и столь же стремительно создает новые проблемы в области социально-трудовых отношений.

Следует констатировать, что в негосударственном секторе экономики профсоюзная деятельность развивается крайне медленно, и это обусловлено многими факторами, прежде всего: низкой квалификацией рабочих, их политической неграмотностью, равно как и не владением знаниями по действующему законодательству, хотя последним нередко страдают и сами предприниматели. При этом они препятствуют созданию на предприятиях профсоюзных организаций, а также стремятся обеспечить свою прибыль за счет нещадной эксплуатации трудящихся.

Защищать права работников в этих условиях становится крайне сложно, но и допускать существование незащищенной трудовой деятельности нельзя. Поэтому профсоюзы, прежде всего, должны обеспечить финансовую независимость деятельности профработников от работодателя, а также проводить разъяснение для работодателя всех выгод от создания профсоюзной организации, и доказывать, что без помощи профсоюза им вряд ли удастся достичь больших успехов.

Создание новых профсоюзных организаций на предприятиях негосударственного сектора должно быть сопряжено с обеспечением их работоспособности в проведении переговоров, в подписании коллективных трудовых соглашений. Необходимо помогать им в обновлении содержания и способов (формы, модели 
и мероприятия) осуществления профсоюзной деятельности в соответствии с демократическими принципами и развитием рыночной экономики. Методы профсоюзной деятельности на этих предприятиях могут быть разнообразными, такими как: методы убеждения, диалога, переговоров, сотрудничества и борьбы. Главное, чтобы они были направлены на развитие творчества, на повышение эффективности труда и на решение проблем, которые действительно волнуют работников.

Для повышения эффективности деятельности низовых профсоюзов также требуется осуществлять подготовку профработников путём организации краткосрочных курсов, поскольку их знания порой оказываются далеки от совершенства. Эти функции должны взять на себя профсоюзы высшего уровня, провести повышения их знаний в сфере трудовых законов, связанных с правами и интересами трудящихся, с методами их защиты с тем, чтобы эти профработники могли стать хорошими пропагандистами на предприятиях.

Для обеспечения более эффективной профсоюзной деятельности в целом необходимо внести изменения в саму ее организационную модель, т.е. сменить парадигму в сторону обеспечения права на автономию местному профсоюзу и смягчения роли структурного аппарата. Вышестоящий Профсоюз остается представителем, при этом он помогает нижестоящему Профсоюзу, а также действует в соответствии с его нуждами и пожеланиями. Все задачи профсоюза должны формироваться на низовом уровне и исходить от пожеланий большинства работников. Но при этом необходимо формировать сети надзора сверху донизу для обеспечения контроля профсоюза за соблюдением законов.

Каждый уровень должен работать по определённой программе, что будет способствовать уменьшению ненужных совместных собраний или сокращению их продолжительности, и координацию усилий профсоюз может осуществлять через внутреннюю информационную систему. На заседаниях исполнительного комитета профсоюза всех уровней необходимо большее внимание уделять обсуждению конкретных вопросов по повышению эффективности деятельности Профсоюза.

Также представляется важным развивать научно-исследовательские центры, организовывать проведение опросов - для своевременного осмысления потребностей самих трудящихся, их устремлений и пожеланий, и на этой основе формировать политику профсоюзной деятельности, в том числе вносить предложения в формирование государственной политики по наиболее злободневным проблемам современности. Потребуется развитие профсоюзных центров для осуществления правовой консультации, центров по трудоустройству рабочей силы, по содействию создания новых рабочих мест, по оказанию помощи и поддержки работникам и работодателям в проведении диалогов и переговоров для достижения согласия в трудовых отношениях на предприятиях. Следует также развивать координацию усилий между профсоюзами и департаментами, ведомствами и отраслями в контрольной и надзорной работе на предприятиях, осуществлять регулярный контроль над выполнением правил трудового законодательства с тем, чтобы не было его нарушений и не происходили несанкционированные забастовки.

Вместе с работодателями и инвесторами необходимо прилагать серьезные усилия к строительству жилых домов для работников, коммунальных культурных сооружений и постепенно улучшать материальную и духовную жизнь трудящихся на предприятиях негосударственного сектора. И все это будет способствовать внесению серьезного вклада в развитие рабочего класса, как ведущей силы в строительстве Социалистической республики Вьетнам.

\section{Литература}

1. Трудовой Кодеск СРВ №10/2012/QН13 от 18 июня 2012г. - Ханой: Издво «Труд и Общество», 2012.

2. Закон СРВ о профессионнальных союзах №: 12/2012/QН13 от 20 июня 2012г. Ханой: Изд-во «Труд и Общество», 2012.

3. Конфедерация труда Вьетнама (2014г.). Профсоюз и забастовки, способы разрешения конфликов и некоторые рекомендации для совершенствования законов о забастовках.

4. Нгуен В.В. Профсоюзы с коллективными согласиями и способами разрешения о забастовках / В.В. Нгуен. Ханой: Изд-во «Труд», 2015.

5. Документы к Заседанию вьетнамских профсоюзов, Всеобщая Конфедерация труда Вьетнама. - Ханой: Издательство «Труд», 2012, с. 72.

6. Всеобщая конфедерация труда Вьетнама «О строительстве гармоничных трудовых отношений в предприятиях». Ханой: Изд-во «Труд», 2018.

\section{References}

1. (2012). Trudovoi Kodesk SRV 10. Khanoi: Izd-vo "Trud i Obshchestvo".

2. (2012). Zakon SRV o professionnal'nykh soiuzakh : 12. Khanoi: Izd-vo "Trud i Obshchestvo".

3. Konfederatsiia truda V'etnama (2014g.). Profsoiuz i zabastovki, sposoby razresheniia konflikov i nekotorye rekomendatsii dlia sovershenstvovaniia zakonov o zabastovkakh.

4. Nguen, V. V. (2015). Profsoiuzy s kollektivnymi soglasiiami i sposobami razresheniia o zabastovkakh. Khanoi: Izd-vo "Trud".

5. (2012). Dokumenty k Zasedaniiu v'etnamskikh profsoiuzov, Vseobshchaia Konfederatsiia truda V'etnama., 72. Khanoi: Izdatel'stvo "Trud".

6. (2018). Vseobshchaia konfederatsiia truda V'etnama "O stroitel'stve garmonichnykh trudovykh otnoshenii $\mathrm{v}$ predpriiatiiakh". Khanoi: Izd-vo "Trud". 